\title{
Reactive molecular dynamics simulations of Cyclotrimethylenetrinitramine (RDX): effects of electrical fields
}

\author{
Fang Chen *
}

School of Chemical Engineering and Environment, North University of China, Taiyuan 030051, China;

*f_chen@nuc.edu.cn

Keywords: RDX; ReaxFF; thermal decomposition; electrical field

Abstract. Reactive molecular dynamics simulations (MD) have been performed to investigate how the decomposition of bulk Cyclotrimethylenetrinitramine (RDX) is affected by electrical field. The rate of RDX molecules loss with time and time evolution of the total populations of various key molecules were evaluated by the algorithm of molecule recognition, based on the calculated atom coordinates and velocities.

\section{Introduction}

Cyclotrimethylenetrinitramine (RDX) is considered as one of most important high explosives (HE) and monopropellants with chemical formula $\left(\mathrm{C}_{3} \mathrm{H}_{6} \mathrm{~N}_{6} \mathrm{O}_{6}\right)$ [see Fig.1] since it release a large amount of energy in bulk decomposition. Understanding the complex thermal decomposition processes is essential to obtain an improved model for detonation and to design more efficient high explosives. Molecular dynamics simulation (MD) is a powerful tool that can be used to examine physical and chemical changes occurring at the atomic scale. Previously, the thermal decomposition mechanism of RDX has been intensively studied, the most probably initial step is the dissociation of the $\mathrm{N}-\mathrm{NO}_{2}$ bond [1-5]. In recent years, reactive force field (ReaxFF) [6] has been introduced to describe the complex reactive process for the high explosives [7-14]. Among those studies, Strachan et al [7] simulated the decomposition of shocked RDX at four relative impact velocities using the developed ReaxFF parameters performed with a constant energy MD. Also Strachan et al [8] investigated the initial chemical decomposition behaviour of RDX at three densities and three temperatures based on ReaxFF molecular dynamic simulations. To the best of our knowledge, the effects of electrical field on the thermal decomposition of RDX have not been investigated.

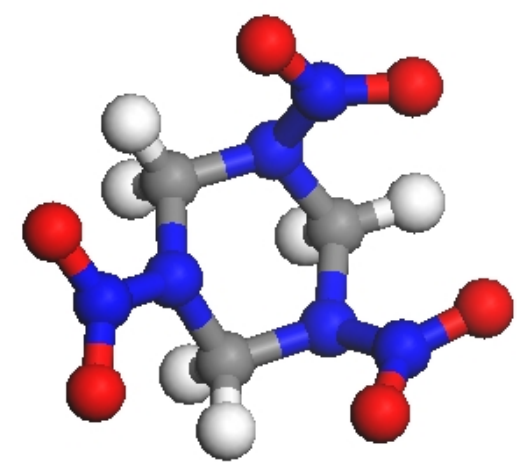

Fig.1. Molecular RDX $\left(\mathrm{C}_{3} \mathrm{H}_{6} \mathrm{~N}_{6} \mathrm{O}_{6}\right)$, gray: carbon; white: hydrogen; red: oxygen; blue: nitrogen.

In this article, we placed 64 RDX molecules in a unit cell measuring $26.364 \AA \times 23.148 \AA \times 21.418$ $\AA$ with 1344 atoms. The electrical fields are exerted to the simulation systems separately. Our goal is to detect how the decomposition of RDX depends on electrical fields. Here we apply ReaxFF MD to provide a detailed analysis of simulation results that allows us to derive the key mechanistic steps responsible for the reactivity trends, providing the basis for the further study of RDX. 


\section{Modeling approach and computational methods}

We model RDX supercell containing a total of 1344 atoms $(2 \times 2 \times 2$ unit cells, 64 RDX molecules). Whose initial positions were taken from the experimentally determined X-ray crystal structure [15]. The crystal structure of RDX has been determined to include eight molecules per unit cell, an orthorhombic structure with lattice parameters $\mathrm{a}=13.182 \AA, \mathrm{b}=11.574 \AA$ and $\mathrm{c}=10.709 \AA$. To generate $\mathrm{a}$ stimulus, all the atoms of the total simulation cell were given an extra electrical field in the $\mathrm{x}$-direction.

We performed MD simulations using the ReaxFF reactive force field implemented in the LAMMPS program [16, 17]. First, the systems were thermalized under NVT conditions at $300 \mathrm{~K}$ for 3 ps. Then, the equilibrated systems were used to perform NVE MD simulations for 12 ps under different electrical fields $(0.5-0.8 \mathrm{~V} / \AA)$. The integration time step in the NVT and NVE simulations of thermal decomposition was set to $0.5 \mathrm{fs}$ and $0.1 \mathrm{fs}$, respectively. During the simulations, the molecule trajectory was recorded. Species for each system was analyzed based on the trajectory.

In order to follow the chemical processes throughout the MD trajectories, we had to determine molecules in the system. This is commonly determined via configuration space: when two atoms are closer than a given cutoff distance, they belong to the same molecule. Here, we apply the modified algorithm of molecule recognition based on the Ref. [8]: two atoms are bonded if they are close in phase space (atomic positions and momenta).

$E_{i j}=V_{\mathrm{int}}^{(i j)}\left(r_{i j}\right)+K^{(i j)}<0$,

Where $V_{\text {int }}^{(i j)}\left(r_{i j}\right)$ is the effective pairwise interaction between atoms $\mathrm{i}$ and $\mathrm{j}$ separated by a distance $r_{i j}$ and $K^{(i j)}$ is their relative kinetic energy. The $V_{\text {int }}^{(i j)}(r)$ term is represented by modified Morse term:

$$
V_{\text {int }}^{(i j)}(r)= \begin{cases}D_{i j}\left(\chi^{2}(r)-2 \chi(r)\right) & \text { if } \mathrm{r}>\mathrm{R}_{i j}, \\ -D_{i j} & \text { if } \mathrm{r}<\mathrm{R}_{i j},\end{cases}
$$

Where $\chi(r)=\exp \left[\gamma / 2\left(1-r / R_{i j}\right)\right]$, the energy of the effective interactions $D_{i j}$ leads roughly to the energy of the $\sigma$ bonds. The distance parameters $\mathrm{R}_{i j}$ are obtained by multiplying the $\sigma$ bond distances by 1.35 . The curvature $\gamma$ equals to 25 .

\section{Results and Discussions}

The rate of Cyclotrimethylenetrinitramine (RDX) molecules loss with time under various external electrical fields is plotted in Fig.2, where we see that the complete decomposition of RDX molecules starts earlier for stronger electrical fields than that for weaker electrical fields, excluding the incomplete decomposition for $0.5 \mathrm{~V} / \AA$ in our simulation time. The RDX molecules decompose entirely at $\sim 8.4 \mathrm{ps}$ for $0.55 \mathrm{~V} / \AA, \sim 5.4 \mathrm{ps}$ for $0.6 \mathrm{~V} / \AA, \sim 4.2 \mathrm{ps}$ for both $0.65 \mathrm{~V} / \AA$ and $0.7 \mathrm{~V} / \AA, \sim 3.3$ ps for $0.75 \mathrm{~V} / \AA$, and $\sim 2.8 \mathrm{ps}$ for $0.8 \mathrm{~V} / \AA$, indicating the increased decomposition of RDX with the increased external electrical field. 


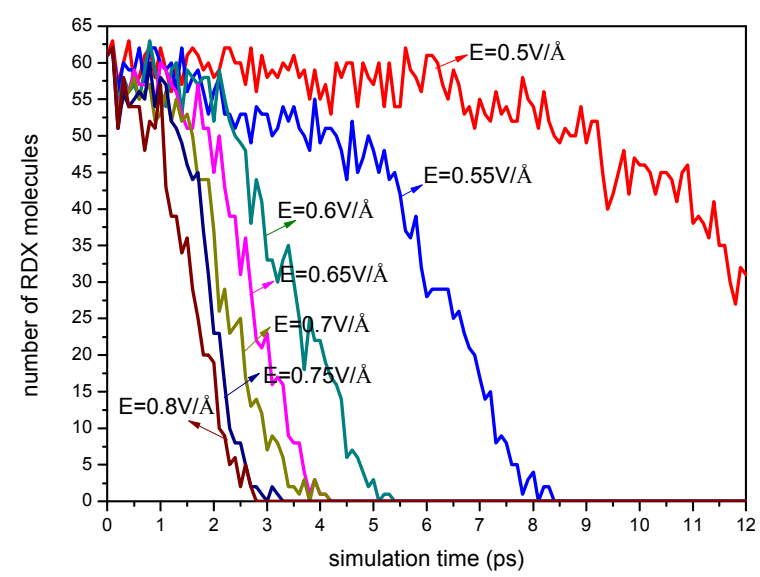

Fig.2. The rate of Cyclotrimethylenetrinitramine (RDX) molecules loss with time under various external electrical fields.

Fig.3a-g plots the evolution of the number of $\mathrm{NO}_{2}, \mathrm{~N}_{2}, \mathrm{NO}, \mathrm{OH}, \mathrm{CO}$, and $\mathrm{CO}_{2}$ molecules at various external electrical fields. Fig. 4 shows the time averaged populations of the key products $\left(\mathrm{NO}_{2}\right.$, $\mathrm{N}_{2}, \mathrm{NO}, \mathrm{OH}, \mathrm{CO}$, and $\mathrm{CO}_{2}$ ) for the various electrical fields studied. The main features can be summarized as follows. (i) The final system temperature reaches up at around $532 \mathrm{~K}$ for $0.5 \mathrm{~V} / \AA$, $2413 \mathrm{~K}$ for $0.55 \mathrm{~V} / \AA \AA \AA, 3709 \mathrm{~K}$ for $0.6 \mathrm{~V} / \AA, 4706 \mathrm{~K}$ for $0.65 \mathrm{~V} / \AA, 6693 \mathrm{~K}$ for $0.7 \mathrm{~V} / \AA, 10229 \mathrm{~K}$ for 0.75 $\mathrm{V} / \AA$ and $14119 \mathrm{~K}$ for $0.8 \mathrm{~V} / \AA$, indicating that higher electrical fields make the system temperature increasing quickly. (ii) $\mathrm{NO}_{2}$ molecules are the most products in the early stage, for instance, the most prevalent products are $\mathrm{NO}_{2}$ molecules for $0.5 \mathrm{~V} / \AA$. Then, under the stronger external electrical fields $(0.55 \mathrm{~V} / \AA$ to $0.8 \mathrm{~V} / \AA)$, the number of $\mathrm{NO}_{2}$ radicals is quickly increased then it is decreased with increased time and temperature. $\mathrm{NO}_{2}$ is found as one of the intermediates from our simulation system, which agrees with previous conclusions for the dissociation of the $\mathrm{N}_{-} \mathrm{NO}_{2}$ bond $[1-5,8,18]$. The stronger the fields applied, the earlier the time of $\mathrm{NO}_{2}$ molecules decreased. For example, the $\mathrm{NO}_{2}$ molecules reaches a maximum of 141 at $\sim 9.3 \mathrm{ps}(\mathrm{T} \sim 1662 \mathrm{~K})$ for $0.55 \mathrm{~V} / \AA, 137$ at $\sim 6 \mathrm{ps}(\mathrm{T} \sim 1602 \mathrm{~K})$ for $0.6 \mathrm{~V} / \AA \AA, 138$ at $\sim 5.3 \mathrm{ps}(\mathrm{T} \sim 1990 \mathrm{~K})$ for $0.65 \mathrm{~V} / \AA, 132$ at $\sim 4.2 \mathrm{ps}(\mathrm{T} \sim 1457 \mathrm{~K})$ for $0.7 \mathrm{~V} / \AA, 130$ at $\sim 4.0 \mathrm{ps}(\mathrm{T} \sim 1935 \mathrm{~K})$ for $0.75 \mathrm{~V} / \AA$, and 129 at $\sim 3.5 \mathrm{ps}(\mathrm{T} \sim 1907 \mathrm{~K})$ for $0.8 \mathrm{~V} / \AA \AA$. These results indicate that the high electrical field promotes the rate of decomposition and makes the transformation of some intermediates products into the stable product more rapidly. (iii) The simulation results also show that the increased electrical field leads to an earlier formation of $\mathrm{N}_{2}, \mathrm{NO}, \mathrm{OH}, \mathrm{CO}$ and $\mathrm{CO}_{2}$ molecules (no $\mathrm{CO}$ and $\mathrm{CO}_{2}$ molecules are formed at lower electric fields than $0.55 \mathrm{~V} / \AA$ on the time scale of our simulation). A small amount of $\mathrm{N}_{2}$ molecules appear at around $10.3 \mathrm{ps}(\mathrm{T} \sim 2121 \mathrm{~K})$ for $\mathrm{E}=0.55 \mathrm{~V} / \AA$. Also we hardly find $\mathrm{CO}_{2}$ molecules but a few $\mathrm{CO}$ molecules emerge for the lower electric fields $(\mathrm{E} \leq 0.65 \mathrm{~V} / \AA)$. There is a downward trend with increased temperature and time for the number of NO, $\mathrm{OH}$, and $\mathrm{CO}_{2}$ molecules under an electric field of $0.8 \mathrm{~V} / \AA$, indicating these molecules react to secondary products under higher electrical field. (iv) The time averaged population of $\mathrm{NO}_{2}$ first increases then it becomes reducing with electrical fields. With increasing electrical fields, populations of $\mathrm{N}_{2}, \mathrm{CO}$ and $\mathrm{CO}_{2}$ slowly increase, while those of $\mathrm{NO}$ and $\mathrm{OH}$ slowly increase then reach equilibrium. 

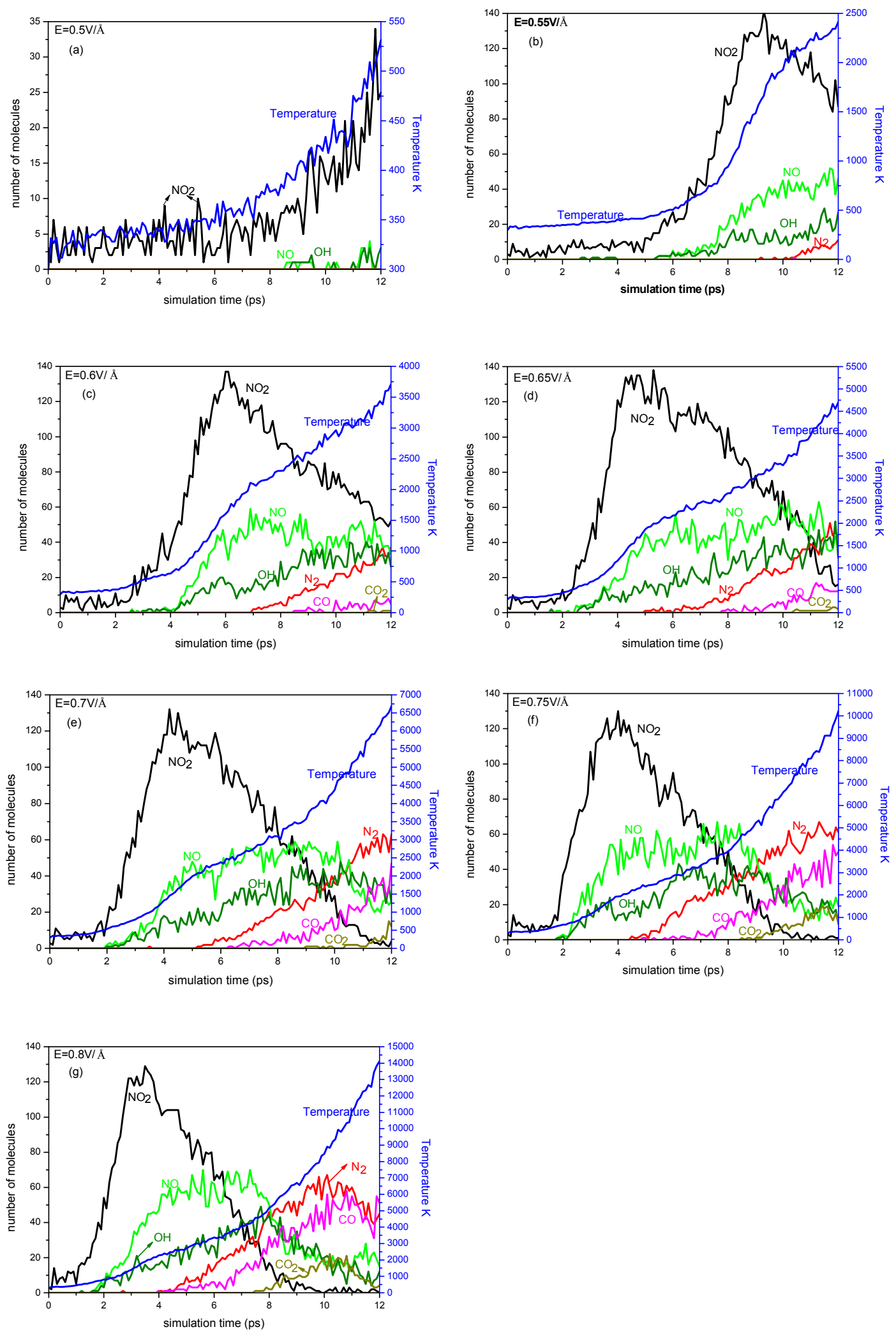

Fig.3. The time evolution of key molecules generated by different electrical fields. (a) $\mathrm{E}=0.5 \mathrm{~V} / \AA$, (b) $\mathrm{E}=0.55 \mathrm{~V} / \AA$, (c) $\mathrm{E}=0.6 \mathrm{~V} / \AA$, (d) $\mathrm{E}=0.65 \mathrm{~V} / \AA$, (e) $\mathrm{E}=0.7 \mathrm{~V} / \AA$, (f) $\mathrm{E}=0.75 \mathrm{~V} / \AA$, (g) $\mathrm{E}=0.8 \mathrm{~V} / \AA$. 


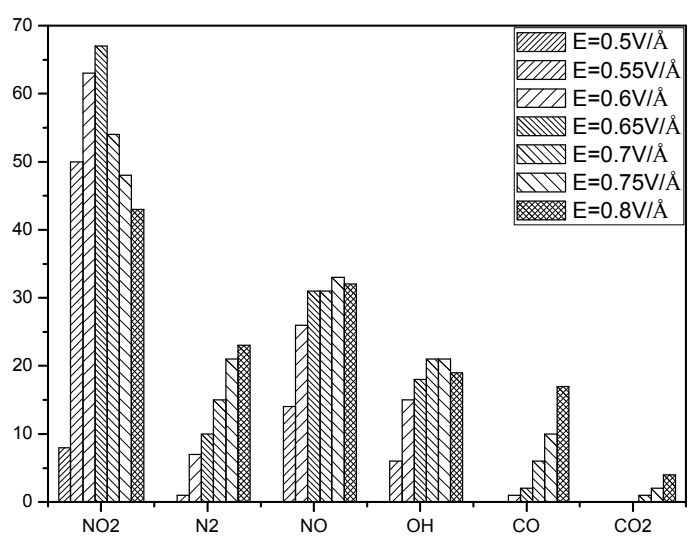

Fig.4. Final population of key molecules for various electrical fields from $\mathrm{E}=0.5 \mathrm{~V} / \AA$ to $\mathrm{E}=0.8 \mathrm{~V} / \AA$

\section{Conclusions}

We have used the ReaxFF reactive force field to study the thermal decomposition process under electrical field for RDX. The following conclusions could be made:

(1) The complete decomposition of RDX molecules starts earlier for stronger electrical fields than that for weaker electrical fields, excluding the incomplete decomposition for $0.5 \mathrm{~V} / \AA$ in our simulation time;

(2) The most prevalent products are the $\mathrm{NO}_{2}$ molecules, indicating that the scission of $\mathrm{N}-\mathrm{NO}_{2}$ is the initial step for RDX pyrolysis;

(3) When the field strength was over $0.55 \mathrm{~V} / \AA$, increasing the electrical field determines rapid decrease of the number of the $\mathrm{NO}_{2}$ molecules and early formation of $\mathrm{N}_{2}, \mathrm{NO}, \mathrm{OH}, \mathrm{CO}$ and $\mathrm{CO}_{2}$ molecules.

\section{Acknowledgments}

Fang Chen thanks the support from the National Natural Science Foundation of China (NSAF. Grant No. 11447219).

\section{References}

[1] C A. Wight, T. R. Botcher, J. Am. Chem. Soc. 114 (1992) 8303-8304.

[2] T. R. Botcher, C. A. Wight, J. Phys. Chem. 97 (1993) 9149-9153.

[3] J. H. Van Esch, M. C. Feiters, A. M. Peters, R. J. M. Nolte, J. Phys. Chem. 98 (1994) 5541-5551.

[4] C. J. Wu, L. E. Fried, J. Phys. Chem. A 101 (1997) 8675-8679.

[5] D. Chakraborty, R. P. Muller, S. Dasgupta, W. A. Goddard, J. Phys. Chem. A 104 (2000) 2261-2272.

[6] A. C. T. van Duin, S. Dasgupta, F. Lorant, W. A. Goddard, J. Phys. Chem. A 105 (2001) 9396-9409.

[7] A. Strachan, A. C. T. van Duin, D. Chakraborty, S. Dasgupta, W. A. Goddard, Phys. Rev. Lett. 91 (2003) 098301.

[8] A. Strachan, E. M. Kober, A. C. T. van Duin, J. Oxgaard, W. A. Goddard, J. Chem. Phys. 122 (2005) 054502.

[9] A. C. T. van Duin, S. V. Zybin, K. Chenoweth, L. Z. Zhang, S. P. Han, A. Strachan, W. A. Goddard, AIP Conf. Proc 845 (2006) 581-584.

[10] L. Z. Zhang, S. V. Zybin, A. C. T. van Duin, S. Dasgupta, W. A. Goddard, AIP Conf. Proc. 845 (2006) 589-592. 
[11] J. Quenneville, T. C. Germann, A. P. Thompson, E. M. Kober, Shock Compression of Condensed Matter. 955 (2007) 451-454.

[12] J. Budzien, A. P. Thompson, S. V. Zybin, J. Phys. Chem. B 113 (2009) 13142-13151.

[13] L. Z. Zhang, A. C. T. van Duin, S. V. Zybin, W. A. Goddard, J. Phys. Chem. B 113 (2009) 10770-10778.

[14] L. Z. Zhang, S. V. Zybin, A. C. T. van Duin, S. Dasgupta, W. A. Goddard, E. M. Kober, J. Phys. Chem. A 113 (2009) 10619-10640.

[15] C. S. Choi, E. Prince, Acta Cryst. B28 (1972) 2857-2862.

[16] Information on http://lammps.sandia.gov/.

[17] S. Plimpton, J. Comput. Phys. 117 (1995) 1-19.

[18] J. C. Xu, J. J. Zhao, L. Z. Sun, Mol. Simul. 34 (2008) 961-965. 